\title{
Telecommunications, Liberalization, and the Growth of the Internet in Turkey
}

\section{Peter Wolcott}

University of Nebraska at Omaha, Omaha, Nebraska, USA

\section{Kursat Çağıltay}

Middle East Technical University, Ankara, Turkey

The privatization and liberalization of telecommunications services have been debated and pursued with varying speed and success by countries throughout the world. In Turkey, efforts to privatize Türk Telekom and liberalize the telecommunications regime have not yet been successful. At the same time, the Internet has experienced dramatic growth. While the experience of Turkey illustrates that formal liberalization of basic telecommunications services is not a necessary condition for the growth of a dynamic Internet services provision market, the relationship between the Internet service providers and the provider of basic telecommunications services remains a critical one. Türk Telekom and policymakers have permitted the creation of a de facto liberal market for Internet services, have supported the creation of Internet infrastructure, and have established a rather level playing field for Internet service providers.

Keywords Internet, Internet service provider, liberalization, privatization, telecommunications, telecommunications policy, Turkey

The privatization and liberalization of telecommunications services have been debated and pursued with varying speed and success by countries throughout the world (Petrazzini, 1995; Mody et al., 1995; Constantelou, 1993; McCormick, 1993; Stehmann, 1995; Stehmann \& Borthwick, 1994; Ure, 1994). In a watershed event in 1997, 69 World Trade Organization member countries signed

Received 15 November 1999; accepted 1 May 2000.

Address correspondence to Peter Wolcott, PKI 177E, University of Nebraska at Omaha, 6001 Dodge Street, Omaha, NE 68182, USA. E-mail: Peter_Wolcott@UNOmaha.edu; Web: http://www.isqo. unomaha.edu/wolcott/pwhome.htm an agreement on basic telecommunications that would improve market access and accelerate regulatory reform (Sisson, 1997). But the details and timetables of implementation continue to be hotly debated in many countries.

During the 1990s the Internet has appeared as phenomenon that is alternately viewed as a powerful force for integrating local economies into the global economy, an engine of economic growth, a force for freedom, a threat to revenue streams of telecommunications providers and their governments, a facilitator of terrorist activities, and a corrupter of social values (Goodman et al., 1998; Press et al., 1998). Whatever one's view of the Internet, it is a powerful medium of communications and commerce. The question may be raised, is the liberalization of basic telecommunication services a necessary condition for the creation of a robust Internet services market?

This article seeks to provide some insight into the question by examining the interplay between efforts to liberalize basic telecommunications services and the emergence of the Internet services market in Turkey. Turkey is one of the largest countries in the Eastern Mediterranean region and a land of contrasts. The only predominantly Muslim country in NATO, Turkey spans the boundary between Europe and the Middle East geographically, culturally, politically, and economically. The tension between the traditional and the modern is a defining quality of Turkish society today and has strongly shaped the evolution of telecommunications and related services. The evolution of the Internet in Turkey offers important insights into factors that may influence the growth of the Internet in other countries that are grappling with the tension between old and new telecommunications regimes, and between local and global issues and interests.

The next section establishes a basic tension found in many developing countries regarding the liberalization of 
telecommunications services. The section that follows traces the development of telecommunications in Turkey. Then we describe the growth of the Internet and the creation of Internet Service Providers (ISP) in Turkey.

\section{LIBERALIZATION OF TELECOMMUNICATION SERVICES}

In most developing countries, telecommunications infrastructure and services have been owned and operated by the government, typically through a postal, telephone, and telegraph administration (PTT). The classical arguments favoring the PTT have been economic, social, and political (Straubhaar, 1995; Petrazzini, 1995; Frieden, 1996). Telecommunications has been viewed as a natural monopoly, with economies of scale and capital investment requirements that make single, centralized providers the most effective means of delivering service. Under a philosophy that telecommunications is a public service that should be available to all citizens, monopolies are held to be the best mechanism for providing universal service, acceptable pricing, and long-range planning. As a vital national infrastructure for integrating and managing a country, particularly in times of crisis, telecommunications has been viewed as a key element of national military and economic security, too important to be left in private hands, whether domestic or foreign (Urey, 1995; Yildizoglu, 1996). Once established, PTTs have provided stable and sizeable revenue streams and sources of employment for their governments, thus developing powerful stakeholders among unions and politicians.

In recent decades, the pressure to liberalize the telecommunications market has come from a number of quarters. Opponents of the PTTs have argued that PTT performance has been inadequate, when measured by such statistics as lines per 100 citizens, the average waiting time for service, and the probability of securing a dial-tone (OECD, 1999b; Frieden, 1996). Business users suffered under the high rates for commercial service used to subsidize rural residential service and the low incentive for the PTTs to invest in advanced digital services. Even when well managed, PTTs in many developing countries have had inadequate resources to expand service. Facing crushing financial crises during the 1980s and 1990s, many governments left little of the PTTs' revenue streams for the PTTs themselves. In some policymaking circles, liberalization was viewed as a key to economic recovery, since a competitive market with a rich offering of advanced telecommunications services would support modern economic activity and make the country more attractive to foreign investment. Liberalization was strongly pushed by international actors. The International Monetary Fund and the World Bank have promoted the liberalization of such services as part of a solution to economic crisis. According to these organizations, liberalization could bring about economic balance and reduced state expenditures. It is almost impossible to obtain new financial support from them without following these conditions (Hills, 1998). The proponents of liberalization do not speak with one voice, however. For some, the state should only be responsible for defense, security, and judicial services; all government assets related to other functions should be sold to private companies. Others feel that education, health, and communications are also the responsibility of the state (Basaran \& Ozdemir, 1998).

The complicated tensions between the forces for and against liberalization have produced a variety of results throughout the world, ranging from a continuation of the status quo to a liberalization of nearly all communications markets, with many intermediate states between these extremes (Ryan, 1997; Petrazzini, 1995). In Turkey, as outlined in the following section, the tension between opposing voices has been strong. While some market segments have been liberalized, basic telecommunications services and many advanced services continue to be provided solely by Türk Telekom, the monopoly provider.

\section{THE DEVELOPMENT OF TELECOMMUNICATIONS SERVICES IN TURKEY}

The Republic of Turkey is a prominent country in the regions surrounding the Black Sea and the Eastern Mediterranean. Slightly larger than the state of Texas, Turkey has a population of approximately 65 million people and a gross domestic product (GDP) of \$3051 per capita (1997). The republic was established in 1923 by Mustafa Kemal, the popular World War I patriot known as "Atatürk," the "Father of Turks." Until his death in 1938, Atatürk introduced a number of social, political, linguistic, and economic reforms that constitute the ideological basis for modern Turkey. Known as "Kemalism," the ideology integrates secularism, nationalism, and modernism and views the West as a source of inspiration and support. Through 1980, Turkey's economy was state-directed, near autarkic, and oriented toward import substitution.

\section{Telecommunications Services Before 1980}

As mandated by the Constitution of 1923 and subsequent revisions, telecommunications services were to be provided by the Turkish government alone. Telecommunications hardware was provided by domestic companies with specialized, and largely nonoverlapping, product lines. The noncompetitive domestic market was protected from foreign competition by government import policies (Akbalik, 1998).

Although the first telephone exchange in Turkey was implemented in 1909, expansion of the telecommunications 
infrastructure proceeded slowly. By 1980, telephone line density had grown to only approximately 2.5 lines per 100 inhabitants. There were nearly as many people waiting for telephone lines as there were lines (1.5 million), yet the number of lines was growing at the very modest rate of 50,000 lines per year. More than $72 \%$ of Turkey's 40,000 villages had no telephone service (Akbalik, 1998).

The years leading up to 1980 were turbulent ones. Turkey's economy was in steep decline, and domestic political violence was claiming 20 victims per day. The Council of National Security (CNS) forcibly restored order on 12 September 1980, banning political activity, dissolving political parties, capturing thousands of terrorists, and confiscating large volumes of weapons and ammunition.

\section{Expansion of Telecommunications Services During the 1980s}

The coup of 1980 marked a turning point for Turkey and ushered in an era of rapid expansion of telecommunications services. In 1980, the CNS began to implement an austerity program architected principally by Turgut Ozal, Deputy Prime Minister from 1980-1982. The program was based on a philosophy of greater reliance on market forces, decentralization, export-led development, lower taxes, foreign investment, and privatization. During the 1980s, the Ozal administration was able to rule without coalition partners and made economic reform its priority. These reforms brought Turkey substantial gains, with the gross national product (GNP) enjoying the highest growth rate of any Organization for Economic Cooperation and Development (OECD) country.

The austerity program crafted by Ozal placed a high value on expansion of telecommunications services, which was viewed as a vital foundation to support an expanded and vibrant economy. The emphasis on telecommunications was motivated from three principal quarters. First, the Army demanded a strong telecommunications infrastructure. The second largest army of NATO did not have a reliable communications system. Second, the open economy espoused by Ozal and others required a quality telecommunications infrastructure. Third, during the early 1980s, the instability in Lebanon was causing many companies to look for safer havens in the Middle East. The lack of a good telecommunications infrastructure was a barrier to attracting these companies (Geray, 1999).

A master plan for telecommunications was drawn up, which emphasized the following themes (Akbalik, 1998):

- Turkey should expand its telecommunications network in the shortest possible time in order to realize rapid economic development.
- New services and the latest technologies should be introduced as quickly as possible.

- The telephone network should be converted from an analog system to a completely digital system.

- To speed up the expansion of telecommunications services, the local telecommunications sector should be pushed towards a genuinely competitive environment.

The effects of the master plan and its implementation soon became evident. Between 1982 and 1986, the total capacity of telephone exchanges increased by $83 \%$. The number of telephone subscribers grew by $80 \%$, and the number of villages having telephone service grew by $162 \%$. At the same time, the telephone company began deploying a variety of new communications services. In 1986 alone, Türk Telekom introduced an experimental packet-switched (X.25) data network, cellular mobile radio telephone system (Nordic Mobile Telephone, NMT), radio paging, and fiber-optic cable (Akbalik, 1998). This same year, Turkey formulated a network expansion plan, which proposed substantial efforts over a 2-year period to decrease the time customers had to wait for new lines and increase to $100 \%$ the number of villages with telephone service. Between 1984 and 1993, annual increases in the capacity of telephone exchanges were usually between 15 and $20 \%$. In 1987, the year of most rapid expansion, the capacity of Turkish telephone exchanges increased by 44.7\% (Akbalik, 1997). By 1988, all Turkish villages had telephone service.

\section{The Struggle to Liberalize Telecommunications Services During the 1990s}

The advances during the 1980s took place in the context of an opening of the Turkish economy, but did not reflect a privatization or liberalization of telecommunications services themselves. Such efforts began in the 1990s, through international and domestic voices espousing the low prices, competition, and better services in telecommunication services that would result from liberalization, and the reduction of national debt that would result from privatization.

During the 1990s, however, weak and uncertain governments and strong entrenched interests have prevented the country from following through on many of the reforms initiated in the previous decade. The Turkish government's inability to limit expanding fiscal deficits and high transfers to inefficient state economic enterprises led to an economic crisis in 1994 in which the Turkish Lira depreciated $135 \%$ against the U.S. dollar in 4 months, and inflation rose to 33\% per month. From 1993 to 1994, the Turkish economy contracted by $11 \%$. An austerity program implemented in April 1994 helped the economy grow in 1996 and 1997. 
Turkey's economy has recovered somewhat during the latter half of the 1990s, although structural reform efforts have had only partial success. The principal economic problem remains inflation, which in 1998 was 75\% annually. The government has failed to seriously improve the efficiency of tax collection and the streamlining of the social security system, both of which are necessary to relieve pressure on the state budget.

An area of relative success has been privatization. Although sales of state economic enterprises have been below the targets set for the privatization program, Turkey did sell $\$ 3.2$ billion in public assets in the first half of 1998 , almost as much as in the years 1986-1997 combined. One of the most important enterprises currently in the process of being privatized is Türk Telekom, the state telecommunications company.

Until 1994, the postal and telecommunications services were provided by the PTT, which was under the control of the Ministry of Transport and Telecommunications. In 1994, the parliament passed a law that split the post and telecommunications functions, incorporating the telecommunications division as Türk Telekom, a joint stock company whose shares are $100 \%$ owned by the government. In this year, the government began an effort to privatize Türk Telekom.

In the case of Türk Telekom, privatization means that $20 \%$ will be sold to a strategic partner; $14 \%$ will be sold to other private investors; $5 \%$ will be set aside for employees of the Post Office and Türk Telekom; the postal service will receive 10\%; and the government will retain 51\% ("Turkey: Turkish Telecom Privatization," 1998). Although efforts have been underway since 1994 to privatize the company, progress has been slow, government proclamations notwithstanding ("Turkey: Coalition Protocol Details," 1996; “Operation To Persuade MHP,” 1999; Gurek, 1998). First, Türk Telekom is the largest taxpayer in the country, and a major source of revenue to the state treasury. Since Turkey suffers from perennial budget deficits, many politicians are reluctant to lose this direct contribution to state revenue. Second, it is a large employer with extensive patronage. Third, there exist unresolved issues with regard to national security. Would the government be able to monitor calls placed through a private telecommunications company? Fourth, the stake to be sold to private investors is small enough that there are few international telecommunications companies who are deeply interested in the company. Furthermore, those that have expressed an interest have done so on the condition that the company would retain its monopoly position in Turkey.

Eventually, Türk Telekom will be privatized. As a signatory of the World Trade Organization, Turkey is obligated to privatize the provision of telecommunications services by the year 2005 at the latest. In the meantime, however, efforts to liberalize telecommunications legislatively appear to have ground to a halt.

\section{Liberalization by Fact, Not by Law}

Although efforts to date to privatize Türk Telekom have been unsuccessful, policymakers have undertaken a number of measures that have produced open, competitive markets in a number of market segments. These measures have been accompanied by selective definitions and policy nuances that have enabled some liberalization to occur, in spite of a lack of direct support in the Constitution and legislation passed by the Turkish Parliament. There are three prominent examples: cellular phone service, international leased circuits, and Internet services.

The analog Nordic Mobile Telephone (NMT) network was introduced in Turkey in 1986. The greatest dynamic in the mobile phone market began, however, when Turkey chose in 1990 the Global Standard for Mobile Communications (GSM) as its mobile phone standard, and licensed two consortia, TurkCell and TelSim, to offer services. GSM service became available in 1993 (Ghazzaoui, 1996). The choice of GSM was closely tied to Turkey's efforts to become a member of the European Union.

The legal arrangements under which organizations other than Türk Telekom could provide cellular phone service were not easy to establish. In order to preserve the constitutional mandate that the government provide and operate telecommunications services, Türk Telekom established a revenue-sharing agreement under which TurkCell and TelSim could offer GSM service. Only after constitutional and security issues were resolved were the companies formally licensed, on 27 April 1998 (Akbalik, 1998; Cetinkaya, 1998). The position of Türk Telekom was that, although the Constitution required the government to provide communications services, it was not a violation for other organizations to provide services provided they did so under license from the government. Under this license, the GSM providers are permitted broad leeway in providing service and in pricing. However, when they need to build terrestrial infrastructure, for example, to lay an E1 (2048 kbps) cable between two ground stations, they must obtain permission from Türk Telekom. Türk Telekom is likely to grant that permission only if it is unable to provide the line itself. (Because of lack of a strong regulatory board, the GSM operators do not always follow the requirements of the contract, which include requirements for quality of service. Following the two strong earthquakes of 1999, the GSM systems did not work for a long time; these companies were strongly criticized by the public.)

Similar reasoning was applied to the provision of international leased circuits. In 1997, Türk Telekom opened up an avenue through which many Turkish organizations have obtained international links. It licensed three 
companies as so-called international business service (IBS) providers. They provide satellite connections to some of the major international connectivity providers. The IBS providers are licensed under a revenue-sharing agreement in which a substantial fraction of the revenue goes to Türk Telekom.

The Internet represents the most dynamic example of de facto liberalization of communications services in Turkey. It is the leading example of a new economic model, not based on revenue sharing, that is working its way into the Turkish communications regime.

\section{THE GROWTH OF THE INTERNET IN THE REPUBLIC OF TURKEY}

\section{The Birth of the Internet in Turkey}

In 1986, a BITNET connection was established between Ege University in Izmir and the European Academic and Research Network (EARN) via Pisa, Italy, through a 9600bps leased line (Tonta \& Kurbanoglu, 1993; Ozzit et al., 1995). The network was named the Turkish Network of Universities and Research Institutes (TÜVAKA) and was administered by a committee consisting of representatives of each participating organization.

The first activities to establish an Internet Protocol (IP) based network started in 1989. In 1991 the initial request for connection to the Internet was sent to NSFNET. In 1993, the Middle East Technical University (METU) and the Turkish Scientific and Technical Research Council (TÜBITAK) established a dedicated 64-kbps Internet connection between METU and NSF with funding from the state planning organization. At the same time, METU and TÜBITAK also formed an informal organization known as TR-NET to promote the use of Internet technologies throughout Turkey (Özgit et al., 1995 ).

By early 1995, the number of hosts had grown to nearly 3000 and the total number of daily users was estimated to be between 10,000 and 15,000. Of these users, more than 1300 had individual connections; others access TR-NET through more than 100 connected institutions. Personal applications were being received at the rate of about 200 per month (Ozgit et al., 1995). At these levels of usage, the international link to NSF was saturated. The link was upgraded to $128 \mathrm{kbps}$ in October, 1995.

To address the growth issues, individuals at TR-NET in 1995 proposed a plan consisting of technical, organizational, and funding components (Özgit et al., 1995). The technical component envisioned a triangular backbone, connecting the three most populous Turkish cities: Ankara, Istanbul, and Izmir. The organizational component envisioned a layer of service providing organizations at each of the three backbone nodes, which would provide Internet information, connectivity, and consulting services to both institutional and individual end users. Users would not connect directly to the backbone.

The funding model envisioned government support to build the backbone and provide operating funds in the short term. Service provider organizations would charge users and, in turn, would be charged for the use of the backbone. As the volume of use, and hence income, increased, the government would gradually reduce its funding until the entire network became self-supporting. Özgit and others envisioned that this would take 2-3 years. METU and TÜBİTAK approached government funding organizations and Türk Telekom with this plan.

\section{Establishing a Liberal Internet Services Market}

The Creation of TURNET. Until 1995, Türk Telekom had taken a rather relaxed attitude toward the Internet, even though one might argue that the Internet represented a new form of communications that should be under Türk Telekom's jurisdiction. This attitude was in part a result of a lack of awareness on Türk Telekom's part of the significance of the Internet, and in part a function of the embryonic, experimental nature of the networks in Turkey. When TÜBITAK and METU approached Türk Telekom in 1995, however, the company began to take a direct interest. Questions were raised about the constitutionality of having organizations other than Türk Telekom provide services; moreover, the previous 15 years of telecommunications development had created a precedent of Türk Telekom's expanding services into emerging areas.

Türk Telekom undertook the development of a national Internet backbone. One requirement was that the backbone should be provided under an arrangement that would preserve Türk Telekom's mandate to be the sole provider of communications services. Prohibitions against private companies carrying third-party communications traffic were finessed by defining computer-based communications as value-added, rather than basic, services. Türk Telekom did not have the resources or expertise to manage a large Internet service provider operation to hundreds of thousands of end users. The model that emerged was one in which Türk Telekom owned the backbone, called TURNET; end users would be served by service-provider organizations that would be required to connect to the backbone. Internet service providers would have to route their international traffic through TURNET's international gateways; independent satellite links were not permitted.

The prospects of finding the funds within its own budget to build a backbone were almost nonexistent. Because it is a government organization, Türk Telekom returns all of its annual revenue to the government. In turn, Türk Telekom receives an annual budget from the state treasury, as outlined by the state planning organization. Any 
money to be used for investment must be approved by the Treasury and the state planning organization and be explicitly included in Türk Telekom's budget. The company is not permitted to borrow money or sell equity to finance investments as private companies do (Basaran \& Ozdemir, 1998). In 1995, the year following the introduction of the 1994 government austerity program, the prospects of obtaining funding for what was still a technology virtually unknown to policymakers, the press, and the general population were vanishingly small.

Türk Telekom fell back on the only alternative model it knew for financing new development: revenue sharing. Under a revenue-sharing model, Türk Telekom partners with an organization to undertake a development project. The partner provides all of the investment capital, and often a portion of the expertise. Türk Telekom and the partner divide the revenue from the project in negotiated proportions. The revenue portion Türk Telekom receives is very attractive because it does not need to be turned over to the state treasury. Türk Telekom has control over these funds and, for the most part, spends them as it wishes.

On 28 September 1995, Türk Telekom announced a tender for the creation of an Internet backbone for Turkey. An auction followed in October and November, and before the first annual Internet conference at Bilkent University, the consortium of GlobalOne, Satko, and METU was announced as the winner, with an offer that $70.2 \%$ of revenue would go to Türk Telekom. The TURNET contract was signed on 1 March 1996 for a 7-year term. Each year, Türk Telekom's share was to increase, reaching $79.6 \%$ at the end of the seventh year.

The Emergence of Internet Service Providers. Once the award was made to the GlobalOne consortium, discussions began on topology. The topology chosen was that proposed by METU in the spring of 1995 (Özgit et al., 1995). The backbone consisted of three 2-Mbps links, and two 512-kbps international connections from Istanbul and Ankara. TURNET went online in the fall of 1996. Over the next 3 years, the backbone was upgraded, but without change to the topology. Once TURNET went online, the Internet service provider (ISP) market exploded. Before TURNET there were fewer than 10 ISPs. During the first year of operation, the total number of ISPs leasing connections to TURNET increased by $600 \%$, to $69 ; 2$ years later, in 1999, the number had reached 80 . In this same period, the number of subscribers to the Internet increased from approximately 100,000 (mid-1996) to approximately $700,000-850,000$ (mid-1999), or just over $1 \%$ of the population (Çă̆ıltay, 1999).

The barriers to entry for ISPs were relatively low. There were (and continue to be) no licensing fees (or, in fact, licensing) to speak of. The costs are in hardware, connection
TABLE 1

Approximate monthly cost of circuit to the Internet in 1997

\begin{tabular}{|c|c|c|}
\hline & $64 \mathrm{kbps}$ & $1 \mathrm{Mbps}$ \\
\hline Turkey (to TURNET) & $\$ 4,000$ & $\$ 23,000$ \\
\hline Turkey (to USA) & $\$ 7,000$ & $\$ 40,000$ \\
\hline Pakistan (to USA) & $\$ 4,000$ & $\$ 44,000$ \\
\hline India (to USA) ${ }^{a}$ & $\$ 23,000$ & $\$ 110,000$ \\
\hline Jordan (to USA) & $\mathrm{n} / \mathrm{a}$ & $\$ 120,000$ \\
\hline
\end{tabular}

fees, personnel, and operating costs. The technical and economic barriers to entry were lower in Turkey than in many other countries seeking to join the Internet community at that time because of the requirement that all ISPs must connect to TURNET. Table 1 compares the monthly connection costs of Turkish ISPs with that of their counterparts in other countries at a comparable stage in the evolution of the Internet. Unlike the latter, a new Turkish ISP did not need to acquire an international connection. It merely needed to obtain a leased line from Türk Telekom to TURNET, a significantly cheaper and simpler option.

The creation of the ISP market marked a significant shift in the way communications and related services are offered in Turkey. While the legal framework did not change substantially, policy and practice permitted, for almost the first time, private companies to offer communications services under something other than a revenue sharing arrangement with Türk Telekom. ISPs pay a fixed monthly fee for their leased line(s). Other than this, no additional revenue goes to Türk Telekom, and Türk Telekom places no restrictions on the kinds of services that can be offered (including voice over Internet protocol [VOIP], which is prohibited in other countries, like India and Pakistan), or the prices that are charged for these services.

Thanks in part to the ease with which ISPs could connect to TURNET and thus become part of the international Internet, the market for ISPs flourished and the market for Internet services became highly dynamic. Competition for customers is intense. A 50\% drop in 1998 in the prices Türk Telekom charged for leased line connections to TURNET quickly resulted in a corresponding drop in average monthly fees for end users to levels that were close to the average among OECD countries (OECD, 1999a) and an expansion of the user base. Competition has led to some creative marketing strategies. For example, VestelNet, the ISP owned by a leading manufacturer of electronic 
equipment, in May 1999 began offering users a free personal computer when they sign up for 3 years of service at $\$ 30 /$ month. The company has been signing up new users at the rate of 50,000 per month. Leading Turkish banks created their own ISPs, offering reduced connection rates and a waiving of transaction fees for their account holders. For example, İS Bank offers unlimited Internet service just for $\$ 9 /$ month.

For those companies and individuals who participate in the Internet, the new market has created a new set of expectations for such matters as customer service and quality. To compete, ISPs have had to offer a steady stream of new and improved services. They have reduced subscription fees to users. They have had to set up 24-hour call centers to support users. They have had to offer guarantees to users that are completely new to Turkish telecommunications. The ISP market is one of the leading examples of markets in which the buyers have growing influence over the sellers. The trend is spreading to other parts of the Turkish economy.

There remain two principal constraints on ISPs. First, the backbone capacity of TURNET has not increased at a rate commensurate with the growth in ISP connectivity. While the overall capacity of the backbone doubled from 1996 to 1999 , the aggregate capacity of ISP connections increased by $300 \%$ from 1997 to 1999 alone.

Second, ISPs have been restricted in their ability to acquire additional infrastructure. To expand their coverage beyond Istanbul, Ankara, and Izmir, ISPs must lease lines from Türk Telekom. They may not build their own, in general. While international leased lines may be acquired through IBS providers, or from Türk Telekom directly, costs remain high. A 1-Mbps link from Turkey to the United States costs three to eight times as much as a comparable link from Europe to the United States.

TTNet. Although receiving $70 \%$ or more of TURNET revenue appeared on the surface to be very favorable to Türk Telekom, its advantages were somewhat illusory. Under the revenue-sharing contract with GlobalOne, Türk Telekom performed only routine operational management of the backbone and was forbidden to make investments in its expansion. All new investments and payments to investors were paid out of GlobalOne's 30\% share. Under such conditions, the return to GlobalOne on new investments would be minimal. Upgrades were made reluctantly. The operational shortcomings became apparent as early as 1997, and Türk Telekom began an effort to create a new infrastructure through its own investment.

By 1997, awareness of the Internet in policymaking circles was substantially greater than in 1995. Efforts by leading advocates within Turkey had succeeded in convincing many policymakers, including the Minister of Transport and Telecommunications, of the importance of the technology. The Turkish Scientific and Technical Research Council in 1998 issued a report entitled "National Information Infrastructure of Turkey," which received a wide hearing in the press and in policymaking circles ("Current Situation and Trends," 1998). Policymakers, the populace, and the press could not fail to see the attention being paid to the Internet in international circles. The new environment, coupled with the failure of the organizational arrangements on which TURNET was based, convinced Türk Telekom to seek direct funding for the new backbone. The government agreed to allocate $\$ 35$ million for the purchase of equipment and expertise to build a national Asynchronous Transfer Mode (ATM) network, called TTNet. The contract was awarded to Alcatel after a competitive bid (Dennis, 1998).

The topology of TTNet, consisting of approximately 140 points of presence (POP), is shown in Figure 1. TTNet is a quantum improvement over TURNET for a number of reasons. First, it offers a huge increase in both domestic and international capacity. The aggregate capacity around the Istanbul-Izmir-Ankara triangle is increasing by nearly two orders of magnitude. International capacity is increasing more than five times (nearly nine times when an additional E3 of international capacity is added in the near future). Second, the geographic scope of the Internet is expanding far beyond the Istanbul-Izmir-Ankara triangle to the regions where ISPs are not willing to go because of high costs and small markets. While very basic dial-up connectivity at reasonable rates has been available nationwide for some time, TTNet will offer the first multi-Mbps access to the southern and eastern portions of the country. The availability of access through the backbone itself will reduce the load on the intercity public switched telephone network, further improving the quality and availability of the latter service. Third, because much of the backbone is based on a fiber, ATM network, TTNet provides a foundation for offering to customers various value-added services, including quality-of-service levels such as priority routing, security, etc. Fourth, because it offers much enhanced capacity, TTNet is likely to cause the demand for international satellite connections to decrease, causing price reductions.

The TTNet roll-out has taken longer than anticipated. Through much of 1999, Türk Telekom announced that TTNet would begin offering services "next month" ("TTNet to be Completed," 1999). By July/August, traffic finally began moving across some TTNet links in a trial capacity. At the time of this writing, few of the TTNet nodes are operational and the main trunks are not reliable. 


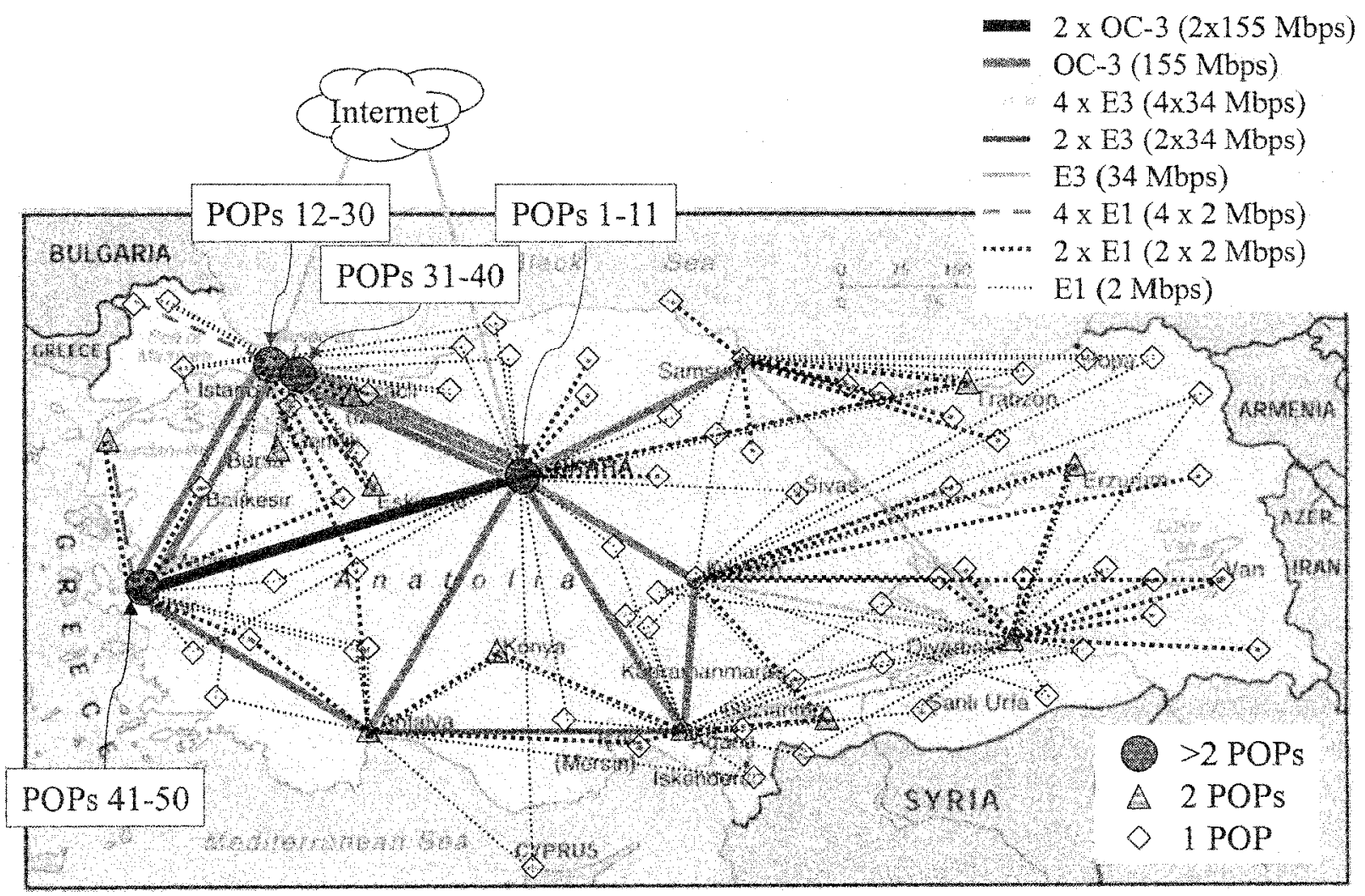

FIG. 1. TTNet topology from Haberler-Duyurular/TTNET/TURK (1999), with permission.

\section{CONCLUSION}

Efforts since 1994 to privatize Türk Telekom and liberalize the provision of basic telecommunications services in Turkey have not yet been successful. Constitutional requirements for a state monopoly on the provision of basic services, resistance among key interest groups, and the lack of a suitable "strategic partner" to purchase a minority stake in Türk Telekom have been key barriers. At the same time, Internet use, capacity, and geographic scope have expanded dramatically in Turkey. The provision of Internet services is characterized by intense competition and rapid growth, as indicated by the approximately $700 \%$ increase in the number of ISPs and Internet users between 1996 and 1999. The evolution of the Internet in Turkey proves that liberalization of basic telecommunications services is not a necessary condition for the growth of a dynamic Internet services market. Countries experiencing difficulty liberalizing their markets for basic telecommunications services may, nevertheless, promote and experience a vibrant Internet services market.

Understanding the mix of factors promoting a robust Internet services market, even in the absence of a liberalized telecommunications regime, is a rich area for future research. Turkey's case suggests that the relationship between the ISPs and the provider of basic telecommunications services is a critical one. While at times frustrating, the dynamic between ISPs, Türk Telekom, and the Ministry of Transport and Telecommunications has been generally positive. First, Türk Telekom has actively sought to create the infrastructure needed to support the expansion of the Internet. These efforts have not always proceeded as smoothly or quickly as desired, but without them the Internet would likely have much lower penetration in Turkey than it does today. Second, Türk Telekom and policymakers have permitted the creation of a liberal market for Internet services. They have adopted definitions and interpretations of the law that permit ISPs to be created, and have lowered many barriers to entry for nascent ISPs. Third, Türk Telekom has not become a dominant ISP itself, although it does provide Internet services. Whether by design or not, the playing field for private ISPs is rather level. Further research is needed to determine the extent to which supportive relationships between ISPs, telecommunications services providers, and government bodies are a shared characteristic of countries experience rapid growth of the Internet.

Further research is also necessary to determine the impact of liberalization of telecommunications on the rate of growth of the Internet. Had multiple companies been 
creating infrastructure and competing for ISP traffic, the Internet might have grown more quickly than it has. A study involving multiple countries, including those that have and have not liberalized the telecommunications regime, is necessary to determine the impact of this factor on the rate of expansion of the Internet.

\section{REFERENCES}

Akbalik, Naci. 1997. Development of Telecommunication in Turkey, Figure4.<http://www.arge.telekom.gov.tr/htms/makalere/figure4.

htm $>$ (21 May 1999).

Akbalik, Naci. 1998. Development of Telecommunication in Turkey. $<$ http://www.arge.telekom.gov.tr/htms/makaleler/devoftt.htm>

(21 May 1999).

Basaran, F., and Ozdemir, O. 1998. Telekomunikasyon: Telekomunikasyonda ozellestirme. Ankara: Kamu Isletmeciligini Gelistirme Merkezi Vakfi.

Çağıltay, Kursat. 1999. Bilgisayar sayisi (Quantity of Computers). July 1999. <http://php.indiana.edu/ kursat/hosts/page3.html > (14 September 1999).

Cetinkaya, Serdar. 1998. Cellular Service Proj. U.S. Foreign Commercial Service, December 31, 1998. <http://www.tradeport.org/ts/ countries/turkey/mrr/mark0010.html > (23 June 1999).

Constantelou, Natasha. 1993. Liberalizing telecommunications markets: Political externalities in the Greek case. Telecommunications Policy 17(6):431-445.

Current Situation and Trends in the World. 1998. Executive Summary. Turkish National Information Infrastructure Project (TUENA), Ministry of Transport. January.

Dennis, Sylvia. 1998. Turkey plans \$35 million national Internet backbone. Newsbytes 15 October.

Frieden, Rob. 1996. International telecommunications handbook. Boston: Artech House.

Geray, Haluk. 1999. Network policy formulation between idealist and strategic models: A political economy perspective from Turkey. Telecommunications Policy 23:495-511.

Ghazzaoui, Ramez. 1996. Privatization and Deregulation in Turkey. 4 July 1996. <http://www.armory.com/ turkiye/it/privpage.html> (29 May 1999).

Goodman, Seymour E., Burkhart, Grey E., Foster, William A., Press, Laurence I., Tan, Zixiang Alex, and Woodard, Jonathan. 1998. The global diffusion of the Internet project: An initial inductive study. Fairfax, VA: MOSAIC Group.

Gurek, Harun. 1998. Telekom \$10 billion. Istanbul Milliyet 1 May:9.

Haberler-Duyurular/TTNET/TURK TELEKOMUNIKASYON A.Ş. 1999. <http://www.telekom.gov.tr/ttnet/haber-port-son.html> (24 June 1999).

Hills, J. 1998. U.S. rules. OK? Telecommunications since the 1940s. In Capitalism and the information age: The political economy of the global communication revolution, eds. R. W. McChesney, E. M. Wood, and J. B. Foster, pp. 99-121. New York: Monthly Review Press.

McCormick, Patricia K. 1993. Telecommunications privatization issues: The Jamaican experience. Telecommunications Policy 17(2): $145-157$.
Mody, Bella, Bauer, Johannes M., and Straubhaar, Joseph D., eds. 1995. Telecommunications politics: Ownership and control of the information highway in developing countries. Mahwah, NJ: Lawrence Erlbaum Associates.

Mosaic Group. 2000. The Global Diffusion of the Internet Project. $<$ http://mosaic.unomaha.edu/gdi.html >

Operation to Persuade MHP. 1999. Istanbul Milliyet 13 May:7.

Organization for Economic Cooperation and Development. 1999a. OECD Internet Access Price Comparison. <http://www.oecd.org/ $\mathrm{dsti} / \mathrm{sti} / \mathrm{it} / \mathrm{cm} / \mathrm{stats} / \mathrm{isp}$-price99.html > (6 March 2000).

Organization for Economic Cooperation and Development. 1999b. A Review of Market Openness and Trade in Telecommunications. OECD, September 1999. <http://www.oecd.org/dsti/sti/it/ cm/prod/tisp99-5e.html > (8 February 2000).

Özgit, Attila, Çağıltay, Kürsat, and Taner, Erdal, 1995. Turkish Internet (TR-NET): Policies for Organizational Framework and Funding. 30 April 1995. <http://isoc.bilkent.edu.tr/HMP/PAPER/ 102/html/paper.html> (29 May 1999).

Petrazzini, Ben A. 1995. The political economy of telecommunications reform in developing countries: Privatization and liberalization in comparative perspective. Westport, CT: Praeger.

Press, Larry, Burkhart, Grey, Foster, Will, Goodman, Seymour, Woodward, Jon, and Wolcott, Peter. 1998. An Internet diffusion framework. Communications of the ACM 41(10):21-26.

Ryan, Daniel J., ed. 1997. Privatization and competition in telecommunications: International developments. Privatizing Government: An Interdisciplinary Series, eds. Simon Hakim, Gary Bowman, and Paul Seidenstat. Westport, CT: Praeger.

Sisson, Peter. 1997. The new WTO telecom agreement: Opportunities and challenges. Telecommunications September:24-40.

Stehmann, Oliver. 1995. Network liberalization and developing countries: The case of Chile. Telecommunications Policy 19(9):667684.

Stehmann, Oliver, and Borthwick, Rob. 1994. Infrastructure competition and the European Union's telecommunications policy. Telecommunications Policy 18(8):601-615.

Straubhaar, Joseph D. 1995. From PTT to private: Liberalization and privatization in Eastern Europe and the Third World. In Telecommunications politics: Ownership and control of the information highway in developing countries, eds. Bella Mody, Johannes M. Bauer, and Joseph D. Straubhaar, pp. 3-30. Mahwah, NJ: Lawrence Erlbaum Associates.

Tonta, Yasar, and Kurbanoglu, S. Serap. 1993. Networked Information in Turkey. January 1993. <http://yunus.hun.edu.tr/ tonta/papers/ network2.html > (29 May 1999).

TTNet to be completed in a month. 1999. Dünya Gazetesi 4 March.

Turkey: Coalition protocol details policy. 1996. Turkish Daily News 4 March:1. FBIS-WEU-96-049.

Turkey: Turkish telecom privatization contract signed. 1998. Ankara Anatolia in English 1632 GMT 27 August 98. FBIS-WEU-98-239.

Ure, John. 1994. Telecommunications, with Chinese characteristics. Telecommunications Policy 18(3):182-194.

Urey, Gwen. 1995. Telecommunications and global capitalism. In Telecommunications politics: Ownership and control of the information highway in developing countries, eds. Bella Mody, Johannes M. Bauer, and Joseph D. Straubhaar, pp. 53-83. Mahwah, NJ: Lawrence Erlbaum Associates.

Yildizoglu, E. 1996. Globallesme ve Kriz. Istanbul: Alan. 